\title{
Epothilone Compound
}

National Cancer Institute

\section{Source}

National Cancer Institute. Epothilone Compound. NCI Thesaurus. Code C1922.

A class of compounds isolated from the myxobacterium Sorangium cellulosum. Similar to taxanes, epothilone compounds induce microtubule polymerization and stabilize microtubules against depolymerization conditions, thereby inhibiting mitosis. ( $\mathrm{NCl})$ 